\title{
Categorias do ser \\ e biologia
}

NELSON PAPAVERO

- JAIR MINORO ABE

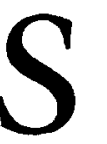

e considerarmos que Sócrates, após ter crescido por um certo período de tempo, pára de crescer e começa a encolher (na velhice), tornando-se então mais baixo, temos que Sócrates deixou de ser o que era (alto); por outro lado, Sócrates nunca deixou de ser um homem.

Como pode Sócrates deixar de ser (alto) e continuar a ser (homem)?

A resposta a este paradoxo é que estamos operando com duas diferentes categorias do ser, ou com dois diferentes tipos de predicaçáo relativos a um mesmo objeto (no caso, Sócrates) - uma mudança de relação nảo implica necessariamente em mudança de substância.

Aristóteles e as categorias

Em grego, o verbo etmai pode ser utilizado de duas maneiras distintas: de maneira existencial (no sentido de existir ou baper) e de maneira atributiva (no sentido de ser ou estar). Aristóteles tinha plena consciência dessa equivocidade e distinguia a pergunta "De que é (feita) esta coisa?" da pergunta "Existe tal coisa? ", ambas utilizando o mesmo verbo elnai.

Mas mesmo dentro de seu uso atributivo (também chamado copulativo) de ser ou estar, o verbo ênai não é unívoco; continua ambíguo. Aristóteles insistia, conseqüentemente, que "ser se diz de várias maneiras". Essas diversas maneiras de dizer-se o verbo serem seu uso atributivo ou copulativo sáo as categorias. Por essa razão há tantas categorias como tipos de predicados e é por isto que a palavra grega kategorla significa predicado, atributo, qualidade atribuida a um objeto (primitivamente significava acusação, por oposiçáo a apologia).

Nos enunciados simples construídos com o verbo ser, o predicado 
indica $o$ que se atribui ao sujeito, e o verbo que se atribui o predicado ao sujeito. Outros verbos cumprem as duas tarefas simultaneamente indicam o que se atribui ao sujeito e que esse predicado é atribuído ao sujeito. Pode-se dissociar ambas as funçóes, separando a cópula (que une o sujeito ao predicado, para formar um enunciado) do próprio predicado, dizendo-se, por exemplo, em vez de Aristóteles disseca um animal, Aristóteles está dissecando um animal; em vez de Aristóteles filosofa, Aristóteles está filosofando. Assim, pois, quase todo enunciado simples e afirmativo pode ser reduzido ao esquema $S$ é (ou está) $P$, onde $S$ é o sujeito, $\mathrm{P}$ é o predicado, e $\dot{e}$ (ou está) é a cópula que indica a atribuiçáo de $\mathrm{P}$ a $S$.

As categorias (do ser) são os diversos modos de atribuiçáo, os diversos tipos de predicação, os diversos significados do verbo ser - as diversas possibilidades de predicar ou dizer alguma coisa de outra (Mosterín, 1984).

Como dizia Aristóteles (Analytikà prótera 49 a 6):

"Coisas que se atribuem a uma outra, ou algo que se diz com verdade de outra coisa, podem ser tomadas em tantos sentidos distintos como há categorias".

O primeiro tratamento sistemático das categorias foi feito por Aristóteles, parte no tratado homônimo do Organon, parte na Metafísica.

Aristóteles presumia que nossos modos últimos de apreensão da realidade correspondiam a modos últimos de ser. Nunca considerou seriamente a possibilidade de que a realidade pudesse náo ser em si mesma aquilo que percebemos ou concebemos que seja. $O$ estagirita fixou em dez o número dessas categorias últimas de ser (ou de apreender a realidade). Aqui damos a lista das dez, com seus correspondentes em latim e português:

$\begin{array}{ll}\text { ousia } & \text { substantia } \\ \text { posón } & \text { quantitas } \\ \text { poidn } & \text { qualitas } \\ \text { prós } t i & \text { relatio } \\ \text { pou } & \text { ubi } \\ \text { poté } & \text { quando } \\ \text { keis thai } & \text { situs } \\ \text { échein } & \text { babitus }\end{array}$

substância quantidade qualidade relação onde (lugar) quando (tempo) posição (situação) estado (condição) 


$\begin{array}{lll}\text { poiein } & \text { actio } & \text { atividade } \\ \text { paschein } & \text { passio } & \text { passividade }\end{array}$

Ser uma coisa é somente um único modo de ser - ou seja, o de substancia. A mesma realidade concreta pode incorporar muitos ou todos os modos de ser. Assim, por exemplo, de seu companheiro de Academia, Koriskos, Aristóteles podia predicar vários tipos de coisas:

Koriskos é um homem (substância ou entidade).

Koriskos é (alto de) cinco côvados (ou tem cinco côvados de altura) (quanto).

Koriskos é sábio (qual).

Koriskos é mais alto que Kléon (relação).

Koriskos está na ágora (onde).

Koriskos esteve aqui ontem (quando).

Koriskos está sentado (postura).

Koriskos está calçado (estado ou condição).

Koriskos está empurrando (algo) (atividade).

Koriskos está sendo empurrado (passividade).

Do próprio Aristóteles podemos dizer que foi um homem (substância ou entidade) que viveu em Atenas (lugar) no $4^{\circ}$ século antes de Cristo (tempo), que ensinava filosofia (atividade); acusado de ateísmo (passividade), ficou deprimido (estado) e fugiu para a casa de amigos (relação), etc.

Nos Tópicos, Aristóteles listou essas mesmas dez categorias, mas chamou a primeira o que $e$ ( tò esti), em vez de ousia (I, 103 b 2l). Em outras obras suas reaparece a lista, apesar de faltarem algumas das categorias finais. Na Física, por exemplo, faltam as categorias posifão e estado (V, 225 b 5 ).

Aristóteles só analisou com algum detalhe as quatro primeiras categorias - substância, quanto, qual e relação (e só essas quatro foram posteriormente empregadas pelos Estóicos). De cada categoria perguntava: os predicados que nela se situam têm contrários ou não?; admitem graus - admitem um mais ou menos? Assim, a substancia não tem contrários (nada é contrário a um cavalo), nem admite um mais ou menos (uma coisa não pode ser mais ou menos cavalo que uma outra). A ca- 
tegoria do qual, porém, admite o mais ou menos (pode-se ser mais ou menos culto, mais ou menos moreno, etc.). Considerou também Aristóteles certas relaçóes que só se dáo em uma categoria determinada: a de adquirir determinaçóes contrárias no tempo é própria da substância; a de igualdade ou desigualdade, do quanto; a de semelhança ou dessemelhança, do qual; a da reciprocidade, da relação (Mosterín, 1984).

\section{As categorias e as classificaçóes de objetos}

Ao classificarmos objetos, o problema das categorias do ser faz-se sentir vivamente. Suponhamos, por exemplo, duas bolas de bilhar identicas na forma e existentes no mesmo intervalo de tempo; essas bolas só diferem na categoria espafo, sendo idlenticas nas categorias formae tempo. Ao classificar seres vivos, o problema se torna muito mais complexo. Aristóteles teve esse problema, ao classificar animais. $\mathrm{Na}$ História dos animais (cf. Peck, 1965-70), por exemplo, o filósofo deparou-se com o problema de existirem diferentes sistemas classificatórios (baseados em diferentes categorias), que resultavam total ou parcialmente incongruentes. Tomemos um exemplo do próprio Aristóteles - os animais podem ser classificados diferentemente, se utilizarmos os seguintes tipos de atributos:

1. Meios utilizados pelos animais para se refrigerarem (katdpsyxis).

2. Meios utilizados para se alimentarem ( trophé).

3. Por que os que tomam água fazem isso?

4. Onde passam seu tempo (diatribt).

5. Onde procriam (tokos).

Quanto à katdápsyxis, os animais podem ser classificados em:
A. Refrigerados a ar.
B. Refrigerados a água.
C. Refrigerados pelo ar circundante.
D. Refrigerados pela água circundante.
E. Auto-refrigerados pelo symphyton pneuma.

Quanto ao tropht:

F. Alguns se alimentam no ar (i. $́$, na terra).

G. Outros se alimentam na água.

E por que tomam água? 
H. Para se refrigerarem (=B).

I. Tomam-na durante a alimentação, mas não a utilizam para se refrigerarem.

Em relaçáo à diatribé, existem animais que:

J. Nunca vão à água.

$\mathrm{K}$. Passam algum tempo na água.

L. Passam todo seu tempo na água.

Finalmente, para seu tokos, existem animais que:

M. Procriam no ar (i. é, na terra).

N. Procriam na água.

Algumas classes, baseadas em diferentes tipos de predicação (ou seja, em diferentes categorias), resultam congruentes; por exemplo, todos os animais caracterizados por $B$ são também reunidos sob $H$. Todos os que são agrupados sob $C$ sáo também $F, J$ e $M$; todos os $D$ são $G, M$ e $O$. Mas nem todas as recíprocas são verdadeiras - todos os $I$ são $N$, mas nem todos os $N$ são $I$. Geralmente, as classificaçóes dos mesmos objetos (vivos ou não), baseadas em diferentes conjuntos de predicados, ou categorias, resultam incongruentes, ou uma classificação " corta" a outra (para utilizarmos a expressão empregada por Aristóteles).

Não nos interessa aqui entrar a fundo no problema das classificaçóes biológicas; tais exemplos servem apenas para ilustrar o uso das categorias num campo particular do conhecimento.

\section{As categorias na antiga filosofia hindu}

A antiga filosofia hindu compreende sistemas (darsana) ortodoxos (astika) e não-ortodoxos ( nastika).

Os ortodoxos são todos de origem bramânica e se dividem em:

Samkhya: uma ontologia e uma cosmologia dualísticas.

Yoga: uma sistematização de práticas místicas e ascéticas.

Nyaya: epistemologia, lógica e metodologia.

Purva-mimamsa: metafísica monista.

Vaisesika:ontologia e sistemática realistas.

Os não-ortodoxos compreendem o budismo e o jainismo. 
O sistema que nos interessa de perto é o Vaisesika, por haver instituído um sistema de categorias semelhante ao de Aristóteles. Esse aparecimento paralelo de sistemas de categorias não é de admirar, dada a comum base sintática indo-européia do grego e do sânscrito, como observou Staal (1976: 47).

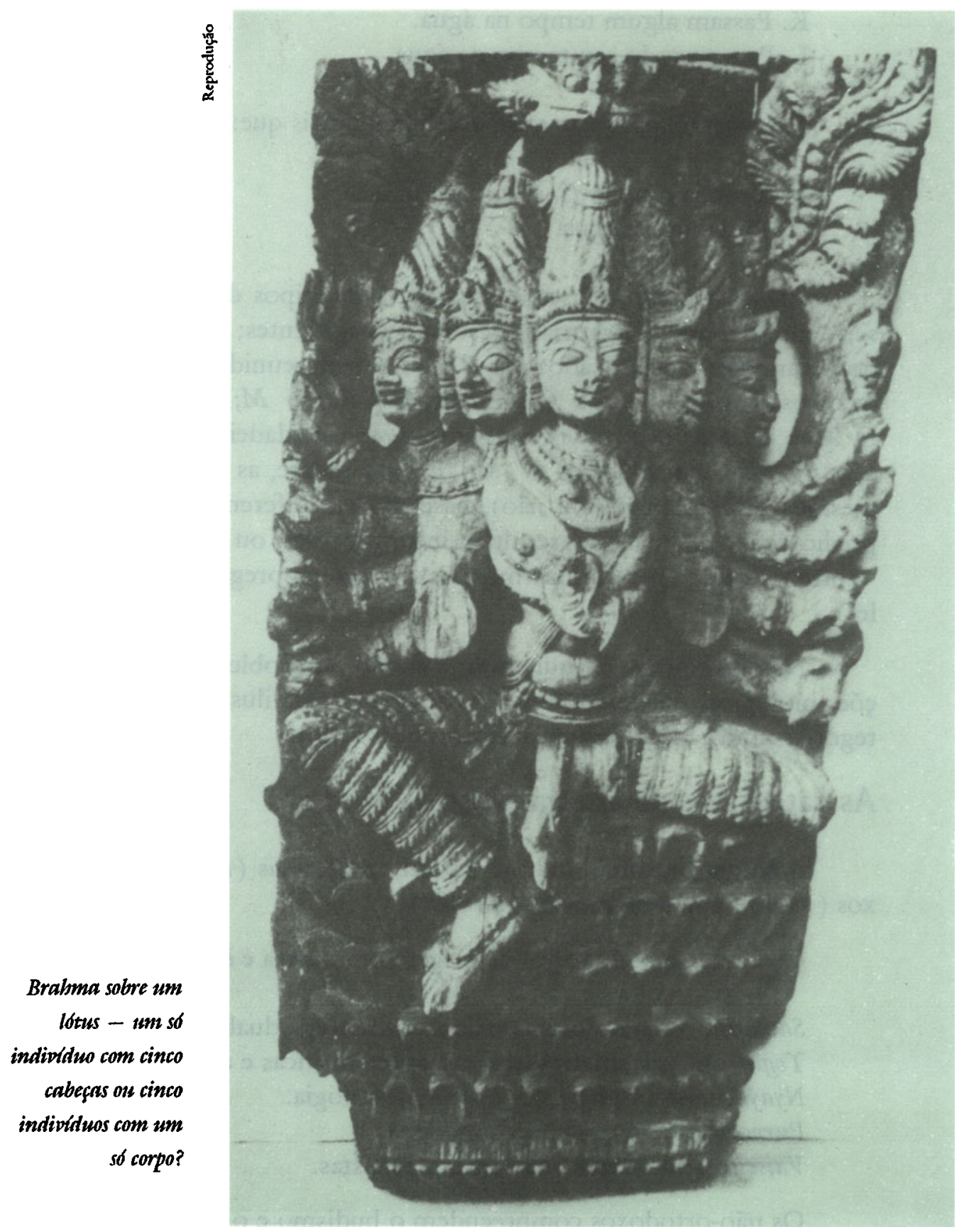




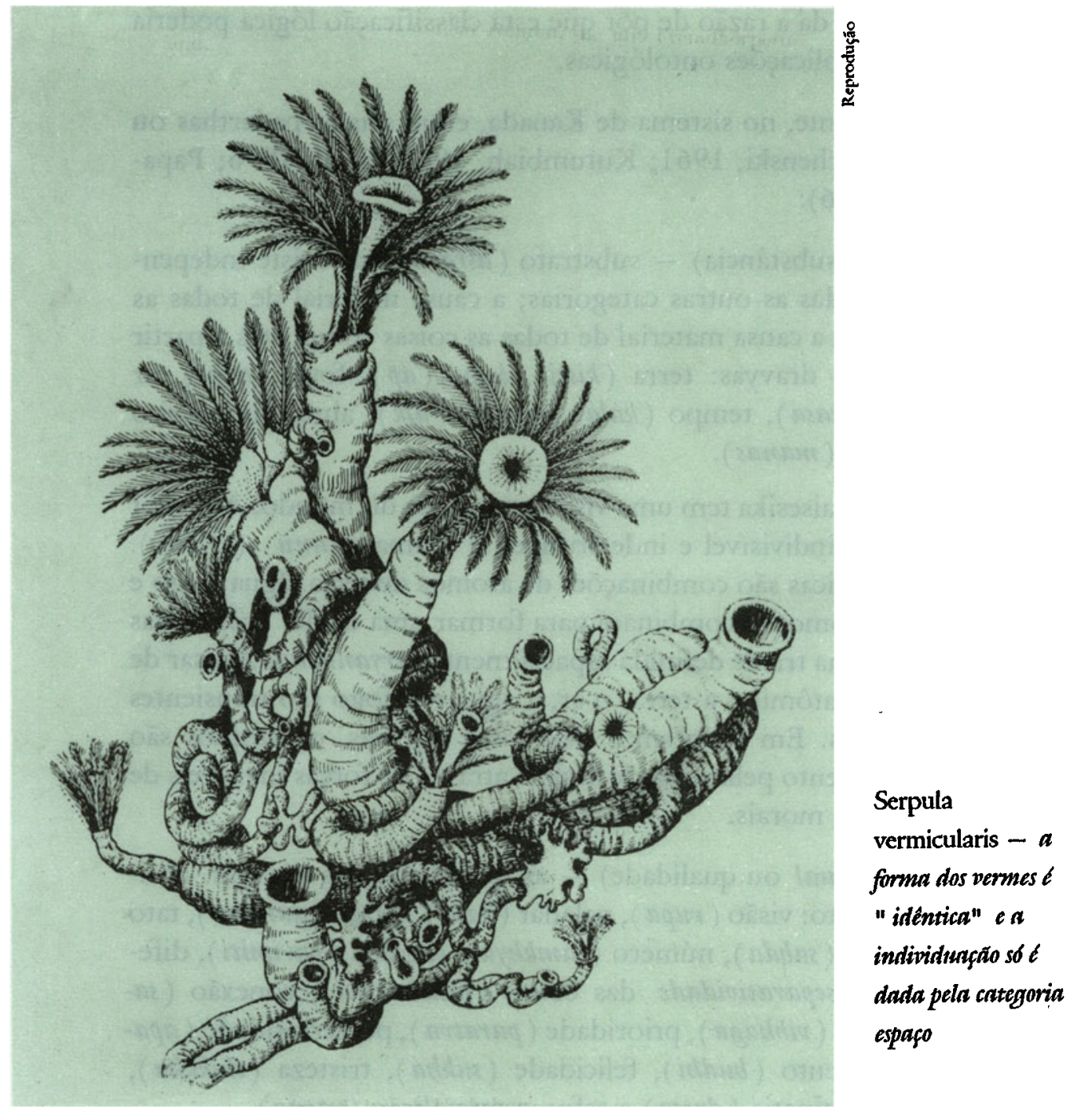

A Kanada (século 2 a.D.) é atribuída a fundação e a primeira sistematizaçáo dessa escola. Importantes comentários e adiçôes foram posteriormente feitos por Prasastapada, Udayana e Sridhara. Após um período de independência, a escola Vaisesika se fundiu com a escola lógica Nyaya, processo completado no século XI de nossa era, surgindo então a escola designada por Nyaya-Vaisesika.

A escola Vaisesika tentou identificar, inventoriar e classificar as entidades e suas relaçóes, tal como se apresentam à percepçáo humana. Para tanto, lançou mão das categorias do ser (padartha), ou seja, uma classificação dos significados (artha) a que se referem as palavras. A ambigüidade do termo artha (como a do inglês meaning), comentou 
Staal (1.c., p. 46), dá a razão de por que esta classificaçáo lógica poderia ter igualmente implicaçóes ontológicas.

Primitivamente, no sistema de Kanada, eram seis as padarthas ou categorias (cf. Bochenski, 1961; Kutumbiah, 1962; Staal, 1976; Papavero \& Balsa, 1986):

1. Dravya (substância) - substrato (asraya) que existe independentemente de todas as outras categorias; a causa material de todas as outras categorias e a causa material de todas as coisas compostas a partir dela. São nove as dravyas: terra (kisti), água (d́p), fogo (tejas), ar (márut), éter (akasa), tempo (kala), espaço (dik), alma ou espírito (atman) e mente (manas).

O sistema Vaisesika tem uma visão atomística do mundo. A menor parte do mundo, indivisível e indestrutível, é chamada anu (átomo). Todas as coisas físicas são combinaçóes de átomos de terra, água, fogo e ar. Dois desses átomos se combinam para formar uma díade. Três dessas díades formam uma tríade definida espacialmente (tryanuka). Apesar de eternos na forma atômica, a terra, o ar, a água e o fogo são transientes quando agregados. Em si mesmos inativos e imóveis, os átomos são postos em movimento pela vontade divina, através de forças invisíveis de mérito e demérito morais.

2. Guna (qual ou qualidade) - as qualidades das dravyas. Basicamente são dezoito: visão ( rupa), paladar ( rasa), olfato (gandha), tato ( sparsa), audiçăo ( sabda), número ( samkbya), medida (parimiti), diferença mútua ou separatividade das coisas (pratbaktva), conexáo (samyoga), separaçáo ( pibbaga), prioridade (paratpa), posterioridade (aparatpa), conhecimento (budbi), felicidade (sukba), tristeza (dukkba), desejo (ichba), antipatia (dvesa) e esforço ou voliçăo (yatna).

Em seus comentários ao Vaisesika-sutra, Prasastapada (ca. séc. 5 a.D.) acrescentou mais cinco gunas: peso (gurutpa), fluidez (drapatpa), viscosidade ( sneha), vestígios ou traços (samskara), virtude (dharma), vício (adbarma) e som.

3. Karma (ou karman) (açáo; também chamada kniya) - sáo cinco: lançar para cima, lançar para baixo, contraçấo, expansão, movimento.

Tanto as gunas como os karmas são inerentes às dravyas, não podendo delas existir independentemente.

4. Samanya (gênero ou caráter genérico; Staal (1976) chama-a jati ) - $\mathrm{o}$ aspecto de generalidade ou identidade que notamos nas coisas; 
toda a percepçáo de identidade das coisas é devida à presença nelas da samanya (por exemplo, reunimos todos os cavalos numa classe por causa de sua capalidade). A samanya denota semelhanças características que permitem que classifiquemos juntos dois ou mais objetos.

5. Visesa (última diferença ou diferença específica) - o que causa a individuaçáo dentro de uma classe - postula-se também para explicar a diferença entre átomos (físicos).

6. Samavaya (inerência) - a virtude pela qual duas propriedades diferentes, como substância e atributo, substância e karma, substância e samanya, causa ( karana) e efeito (karya), etc., parecem tão unidas ao ponto de se nos apresentarem como um todo, ou uma realidade idêntica inseparável.

Mais tarde, uma outra padartha foi acrescentada:

7. Abhava (não-existência ou ausência) - apesar de seu conteúdo negativo, a impressão causada em nós pela abhava é positiva; uma pessoa tem a percepçáo de uma abhava quando sente que falta algo em uma coisa. A abhava se classifica em:

- diferença (A não é $\mathrm{B})$;

- ausência (A não é (está) em B). Há quatro tipos de ausência:

a. ausência prévia - de algo que ainda não existe;

b. ausência posterior - de algo que foi destruído ou que não existe mais;

c. ausência total - tal como a da cor no vento;

d. ausência recíproca - como a de um jarro e uma toalha: um náo é o outro e vice-versa.

Várias outras classificações das padarthas existem. Uma famosa é devida ao grande médico hindu Charaka (século ?), em seu clássico de medicina Charaka Sambita (cf. Kutumbiah, 1962). Charaka dividiu as gunas em qualidades sensíveis (os cinco sentidos) e qualidades mecânicas ou físicas; estas últimas se distribuem em duas listas:

1. Gurvadayah: com vinte qualidades - peso (guru), leveza ( laghu), frio (sita), calor (ushna), viscosidade (snighda), secura (ruksma), inatividade (manda), atividade (riksna), imobilidade (shtira), fluidez ( sara), maciez ( mrdu), dureza (katina), clareza ( pisada), glutinosidade ( picchila), lisura (slaksna), rugosidade ( $k b r a$ ), volume ( stbula), penetratividade (suksma), densidade (sandra), liquidez (drava) e inteligência (buddhi). 
2. Paradayab: com nove qualidades; algumas delas são as mesmas usadas no Vaisesika-sutra, mas tomadas em sentido diferente, de acordo, provavelmente, com a prática médica da época: para (superioridade ou importância); apara (inferioridade ou náo-importância) (superioridade $\mathrm{e}$ inferioridade se referem ao país, ao tempo, à idade e à medida); yukti (seleção adequada de remédios contra certas doenças); samyoga (mistura ou composição - de duas ou mais substâncias); vibhaga (separação); prthaktva (diferença; refere-se a três tipos de diferença: diferença especial, diferença de caracteres e diferença de identidade decorrente da distinção numérica); parimana (medidas através de peso); samskara (produçáo de novas qualidades); e abbyasa (hábito em virtude da prática constante).

\section{Antigas classificações zoológicas hindus}

É óbvio que, assim como percebera Aristóteles, os hindus também devem ter notado que uma classificação de animais baseada em determinada categoria pode ser incompatível com outra, baseada em categoria diferente. Vejamos apenas dois exemplos de antigas classificaçóes zoológicas hindus, parcialmente congruentes - a de Charaka e a de Umasvatis (cf. Seal, 1915; Sarkar, 1918; Sinha \& Shankarnarayan, 1955; Papavero \& Balsa, 1986).

Charaka, no 3\% capítulo de sua obra Sarivasthana, divide os animais em quatro classes, segundo o seu tipo de reprodução:

1. Jarajuya: vivíparos (homem e mamíferos).

2. Andaja: ovíparos (peixes, répteis e anfíbios).

3. Svedaja ou Usmaja: nascidos da umidade e do calor, por geraçáo espontânea (vermes, mosquitos).

4. Udvija: nascidos da matéria vegetal.

A autora jainista Umasvatis (?séc. 6 a.D.), em sua Tattvarthadhigma-sutra, por sua vez, classificou os animais, primeiramente, pelo número de sentidos que apresentam; dentro de cada classe assim obtida, dividiu-os, posteriormente, por outros atributos (p. ex., tipos de apêndices locomotores). Chegou ao seguinte esquema, bastante elaborado para a época:

A. Animais com dois sentidos: sparsa (tato) e rasa (paladar) (sabemos que têm tato por poderem sofrer contração - um dos karmas; sabemos que têm paladar por poderem aceitar ou rejeitar alimentos):

a. Apadika: vermes sem apêndices locomotores. 
b. Nupuraka: anelados com apêndices locomotores laterais não-segmentados.

c. Gandupada: pernas segmentadas (artrópodos).

d. Sankba: alguns moluscos (gastrópodos de concha cônica).

e. Sambuka: gênero Helix (o escargot).

f. Suktika: bivalvos (pelecípodos).

g. Jaluka: sanguessugas.

B. Animais com três sentidos: tato, paladar e gandha (olfato):

a. Pipilika: formigas.

b. Rohinika: formigas vermelhas.

c. Upachika, Kunthu, Tuburaka: percevejos e pulgas.

d. Trapusavija e Karpasasthika: besouros do pepino e do algodão e piolhos.

e. Sathapadi e Uthpataka: colêmbolos.

f. Trinapatra: piolhos dos vegetais.

g. Kastha-haraka: cupins e formiga-leão. são):

C. Animais com quatro sentidos: tato, paladar, olfato e rupa (vi-

a. Bhramara: abelhas.

b. Varatha: certas vespas.

c. Saranga: outros tipos de vespas.

d. Maksika: moscas.

e. Puttika: mosquitos (não-picadores).

f. Dansa: estróideos.

g. Masakas: mosquitos (culicídeos).

h. Vrischika: escorpióes.

i. Nandyapartha: aranhas.

j. Kita: lepidópteros.

k. Pathanga: gafanhotos.

D. Animais com cinco sentidos: tato, paladar, olfato, visão e sabda (audição):

a. Matsya: peixes.

b. Uraga: anfíbios (ápodos).

c. Bhujanga: serpentes (os que reptam sobre seu ventre).

d. Pakshi: aves (com asas).

e. Chatuspada: vertebrados quadrúpedes (e o homem).

Se compararmos as duas classificaçóes, veremos que a classe $\mathrm{D}$ de Umasvatis inclui as classes 1 e 2 de Charaka; as classes 3 e 4 de Charaka, 
entretanto, vão aparecer várias vezes, independentemente, nas classes $\mathrm{A}$, $\mathrm{B}$ e $\mathrm{C}$ de Umasvatis.

\section{Categorias e biologia}

Um organismo pode ser variada e simultaneamente considerado como um sistema genético (ou como um conjunto de genes), como um sistema morfológico (ou um conjunto de caracteres taxondmicos; em particular, no âmbito da teoria da Sistemática filogenética de W. Hennig (1966, 1968), como um conjunto de apomorfias), como um sistema bioquímico (e, portanto, como conjuntos de proteinas, aminodicidos, etc.), como um sistema celular (ou um conjunto de células), e assim por diante.

Cada um desses modos de se per um organismo (ou seja, qualquer um dos modos de apreender a realidade de um objeto, ou um modo de predicaçáo) é considerado uma categoria.

\section{Formalismo conjuntista}

Podemos formalizar um sistema de categorias, de conformidade com a exposição acima. A idéia básica é considerarmos, intuitivamente, um universo de conjuntos e átomos (Urelemente) de tal sorte que satisfaça os axiomas usuais da teoria de conjuntos (por exemplo, a de Zermelo-Fraenkel, $\mathrm{ZF}$ ), acrescido de um número finito de universos menore: $E_{1}, E_{2}, \ldots, E_{n}(n \geq 1)$, tais que cada $E_{i}, 1 \leq i \leq n$, seja um modelo da teoria dos conjuntos com átomos. A novidade consiste em postular os axiomas usuais da Mereologia (lógica das partes e do todo em geral) sobre o conjunto dos átomos de um universo dado. Isto permite que cada universo $\mathrm{E}_{\mathrm{i}}$ (unipersos de Dedecker), $\mathrm{l} \leq \mathrm{i} \leq \mathrm{n}$, possa ser considerado como um ponto de vista ou categoria. Tal formalismo técnico é apresentado em Da Costa, Papavero \& Abe (1991).

A teoria dos universos surgiu em matemática por volta da década de 60 , quando os lógicos necessitaram da formalização da teoria das categorias (aqui na acep̧̧ão que este termo possui em lógica) dentro da teoria dos conjuntos. A razão é que no sistema ZF da teoria dos conjuntos não se podem considerar classes muito grandes, como, por exemplo, a categoria de todos os conjuntos. Para solucionar o problema, vários matemáticos, entre os quais o matemático francês Grothendieck, introduziram a noçáo de universo. Assim, em um tal universo, pode-se considerar a categoria de todos os conjuntos, a categoria de todos os grupos, etc., bém como se podem efetuar todas as operaçóes usuais da teoria dos 
conjuntos. Além de Grothendieck, vários lógicos se dedicaram ao tema, como Sonner, Ehresmann, Dedecker, Da Costa, e outros.

É deveras interessante notar que noçōes consideradas altamente técnicas em lógica, como a de universo, venham a ser instrumento útil, ao menos em uma primeira aproximação, para formalização de teorias das ciências não-formais, em particular a biologia.

\section{Bibliografia}

BOCHENSKI, I. M., 1961. Part VI. The Indian variety of logic, pp. 416-447, in seu $A$ bistory of formal logic. University of Notre Dame Press, Notre Dame.

DA COSTA, N. C. A., N. PAPAVERO \& J. M. ABE, 1991. Set-theoretical foundations of categories in biology. (Instituto de Estudos Avançados, Universidade de São Paulo) Colegato Documentos (SÉrie Logica e Teoria da Ciencia) 7:1-14, 3 figs.

HENNIG, W., 1966. Phylogenetic systematics. University of Illinois Press, Urbana.

HENNIG, W., 1968. Elementos de una sistemditica filogenetica. EUDEBA, Buenos Aires.

KUTUMBIAH, P., 1962. Ancient Indian medicine. Orient Longman, Bombay-CalcuttaMadras-New Delhi.

MOSTER IN, J., 1984. Historia de la filosofia. 4. Aristoteles. Alianza Editorial, Madrid.

PAPAVERO, N. \& J. BALSA, 1986. Introdufáo bistórica e epistemologica di biologia comparada, com especial referencia di biogeografia. 1. Do Génesis no fim do Imperio Romano do Ocidente. Biótica \& Sociedade Brasileira de Zoologia, Belo Horizonte.

PECK, A. L., 1965-70. Aristotle: Historia animalium, 3 vols. W. Heinemann, London \& Harvard University Press, Cambridge, Mass.

PRIOR, A. N., 1976. Historia de la logica. Editorial Tecnos, Madrid.

SARKAR, B. K., 1918. Hindu achievements in exact sciences. Longman, Green \& Co., New York.

SEAL, B., 1915. The positive sciences of the ancient Hindus. Longman, Green \& Co., New York.

SINHA, R. N. \& D. SHANKARNARAYAN, 1955. Concepts of insect taxonomy in ancient India. Ent. Nenss 66: 243-247.

STAAL, J. F., 1976. Lógica india, PP. 39-51, in A. N. Prior, q.v.

\section{Resumo}

As categorias do ser são as distintas maneiras de se ver um objeto - as distintas maneiras de predicação. Um breve histórico do emprego das categorias por Aristóteles e por alguns autores hindus é apresentado. As categorias do ser podem ser formalizadas conjuntistamente e constituem um importante fundamento para as classificaçóes biológicas. 


\begin{abstract}
The categories of being are the distinct manners of "seeing" an object - the different manners of predication. A brief history of the utilization of categories by Aristotle and some Hindu authors is presented. The categories of being may be formalized in ser theory, constituting an important foundation for biological classification.
\end{abstract}

Nelson Papapero é bacharel em Ciências Biológicas pelo Instituto de Biociências (IB) da USP, onde também obteve seu doutorado na área de Zoologia. Foi bolsista da John Simon Guggenhein Memorial Foundation, nos Estados Unidos, e por três vezes presidente da Sociedade Brasileira de Zoologia. Atualmente está licenciado do Museu de Zoologia da USP para atuar como professor visitante do Instituto de Estudos Avançados (IEA) da USP.

Jair Minoro Abe é bacharel e mestre em Matemática Pura pelo Instituto de Matemática e Estatística (IME) da USP e doutor em Filosofia pela Faculdade de Filosofia, Letras e Ciências Humanas (FFLCH) da USP. Foi professor visitante da Universidade de Shizuoka, no Japão, e da Universidade de Concepción, no Chile. Atualmente é professor do IGCE-Unesp e coordenador do Grupo de Lógica e Teoria da Ciência do Instituto de Estudos Avançados (IEA) da USP. 